\title{
Microstructural Development during Welding of Silicon- and Aluminum-Based Transformation-Induced Plasticity Steels-Inclusion and Elemental Partitioning Analysis
}

\begin{abstract}
M. AMIRTHALINGAM, M. HERMANS, and I. RICHARDSON
Microstructural development in gas tungsten arc (GTA) welded silicon- and aluminum-based transformation-induced plasticity (TRIP) steels was studied by optical and electron microscopy. The fusion zone (FZ) of both welds contained complex inclusions. Energy-dispersive spectroscopic (EDS) analysis on these inclusions showed that the center of the inclusions contained oxides of silicon and aluminum in silicon- and aluminum-based steels, respectively. Epitaxial enrichment of manganese, sulfur, and phosphorous was found on the oxides in the inclusions, resulting in depletion of solutes in solid solution and thereby reducing the stability of austenite in the fusion zone. The fusion line of aluminum-based steel weldments contained higher amounts of allotriomorphic ferrite than silicon-based steel weldments due the partitioning of aluminum at the fusion line during solidification. The retained austenite (RA) contents in the heat-affected zones (HAZs) and FZs of both TRIP steels were found to be about 8 and 4 pct by volume, respectively.
\end{abstract}

DOI: $10.1007 / \mathrm{s} 11661-008-9761-5$

(C) The Author(s) 2009. This article is published with open access at Springerlink.com

\section{INTRODUCTION}

ADVANCED high-strength steels (AHSSs) are promising solutions for the production of lighter automobiles, which exhibit reduced fuel consumption and increased passenger safety due to improved crashworthiness. Transformation-induced plasticity (TRIP) steels are one class of AHSSs that offer high strength and toughness combinations with uniform elongation of about 20 to 35 pct. $^{[1]}$ Along with these properties, these steels also have an ability to absorb more energy during a crash due to the delayed transformation of retained austenite (RA) to martensite upon deformation. ${ }^{[2]}$ However, the higher alloying content of these steels limits weldability, and the thermal cycle of a welding process destroys the carefully designed microstructure, which results in inferior mechanical properties of the weld. In order to improve the commercial applicability of these steels, it is necessary to improve weldability by understanding the welding behavior with emphasis on specific welding processes and their thermal cycles, as well as the effects of alloying additions on the evolution of the weld and heat-affected zone (HAZ) microstructures. Cretteur et al. ${ }^{[3,4]}$ attempted to improve the weldability of TRIP steels by pre- and postweld heat treatments during resistance spot welding and reported better mechanical properties with modified weld thermal profiles. Studies on the influence of $\mathrm{CO}_{2}$ laser welding

M. AMIRTHALINGAM, Ph.D. Researcher, is with the Materials innovation institute (m2i), 2600GA, Delft, The Netherlands. Contact e-mail: m.amirthalingam@m2i.nl M. HERMANS, Assistant Professor, and I. RICHARDSON, Professor and Head, Joining and Mechanical Behavior, are with the Department of Materials Science and Engineering, Faculty of 3ME, Delft University of Technology.

Manuscript submitted June 25, 2008.

Article published online February 5, 2009 parameters by Han et al. ${ }^{[5,6]}$ showed porosity formation in the weld beads, resulting in poor mechanical properties. These authors concluded that increasing the speed of welding and lowering the laser power reduced the volume fraction of porosity and improved the properties of the welded material. However, these articles only deal with mechanical properties of the welded TRIP steels, and there is no work so far reported on the microstructrual evolution during welding. The effect of weld thermal profile and alloying additions on the nature and volume fraction of microstructural constituents formed in a given weld thermal cycle should be thoroughly characterized in order to tailor appropriate weld thermal cycles.

In the present work, an attempt has been made to gain more insight into microstructural evolution during welding of commercially processed silicon- and aluminum-based TRIP steels. These steels were welded by means of gas tungsten arc (GTA) welding. The influence of the weld thermal cycles and composition on the nature of microstructrual constituents formed in the HAZ and fusion zone (FZ) after welding were studied. The role of alloying additions such as silicon and aluminum on the phase transformation behavior of TRIP steels during welding was thoroughly analyzed. Their partitioning behavior in the various microstructrual constituents that were formed in a given weld thermal cycle were also studied to understand their role in RA stabilization and inclusion formation in the FZ of the welded TRIP steels.

\section{EXPERIMENTAL PROCEDURE}

Commercial grade and industrially processed high silicon bearing (high-Si) and high aluminum (high-Al) 
Table I. Composition of the Steels under Investigation

\begin{tabular}{lcccccrrr}
\hline Elements, wt pct & $\mathrm{C}$ & $\mathrm{Mn}$ & $\mathrm{Si}$ & $\mathrm{Cr}$ & $\mathrm{Al}$ & $\mathrm{S}$ & $\mathrm{P}$ & $\mathrm{O}$ \\
\hline High-Al & 0.19 & 1.63 & 0.35 & 0.019 & 1.1 & 0.005 & 0.089 \\
High-Si & 0.19 & 1.67 & 1.47 & 0.21 & 0.04 & 0.005 & 0.080 & 0.002 \\
\hline
\end{tabular}

bearing TRIP steels were used in this study. High-Si steel was received in a hot-rolled and annealed condition with a thickness of $3 \mathrm{~mm}$, and high-Al steel was received in a cold-rolled and galvanized condition with a thickness of $1.25 \mathrm{~mm}$. As can be seen from Table I, where the compositions of these steels are given, the total content of alloying elements is about $3.5 \mathrm{wt}$ pct. The carbon and manganese contents in both steels are almost identical. In the high-Si steel, the silicon content is $1.47 \mathrm{wt}$ pct, and in the high-Al steel, the aluminum content is 1.1 wt pct. Apart from aluminum, high-Al steel contains $0.089 \mathrm{wt}$ pct phosphorous, which is almost equal to the phosphorous content of the high$\mathrm{Si}$ steel. Both steels have dissolved oxygen contents of about 0.002 wt pct.

Sample plates for GTA welding experiments with a length of $250 \mathrm{~mm}$ and a width of $100 \mathrm{~mm}$ were cut from the steel plates and subjected to a TRIP heat treatment cycle using salt baths. These heat treatments were performed to eliminate influences due to production conditions and generated the base microstructures for welding experiments. Samples were intercritically annealed at $840{ }^{\circ} \mathrm{C}$ for 30 minutes to obtain a ferriteaustenite microstructure, followed by an isothermal bainitic holding at $400{ }^{\circ} \mathrm{C}$ for 1 minute and subsequent water quenching to room temperature.

Bead-on-plate welding was performed on these heattreated plates using automated GTA welding equipment; the welding parameters used are shown Table II. The welding current and speed were adjusted to generate similar heat inputs during welding of the $3 \mathrm{~mm}$ thick high-Si and $1.25 \mathrm{~mm}$ thick high-Al steel samples.

The GTA welding was carried out using a Migatronic Commander 400 AC/DC (Migatronic Automation A/S, Aabybro, Denmark) power source. An automatic voltage control algorithm was used to keep the voltage constant during welding. The conditions resulted in full penetration welds of about $5-\mathrm{mm}$ width. During welding, the samples were clamped to a steel backing plate with a $20 \mathrm{~mm}$ wide central groove for purging the backing gas (argon). At $125 \mathrm{~mm}$ from the starting edge of the samples, the backing plate has a $20 \mathrm{~mm}$ wide grove perpendicular to the welding direction, to allow thermocouple measurements to be made at the bottom side of the samples. In-situ temperature measurements were performed during bead-on-plate welding using $0.25 \mathrm{~mm}$ diameter $k$-type thermocouples, which were discharge welded to the bottom of the plates on a line perpendicular to the weld seam, starting $5 \mathrm{~mm}$ either side of the weld centerline with interdistances of $3 \mathrm{~mm}$ between measurement points.

After welding, the plates were cross sectioned in the transverse direction for metallographic analysis. Samples were polished and etched for optical microscopy
Table II. Welding Parameters

\begin{tabular}{lll}
\hline Parameters & \multicolumn{1}{c}{ High-Si } & \multicolumn{1}{c}{ High-Al } \\
\hline Electrode & $\mathrm{W}+2$ pct $\mathrm{ThO}_{2}$ & $\mathrm{~W}+2 \mathrm{pct} \mathrm{ThO}_{2}$ \\
Electrode diameter & $2.4 \mathrm{~mm}$ & $2.4 \mathrm{~mm}$ \\
Electrode angle & $60 \mathrm{deg}$ & $60 \mathrm{deg}$ \\
Arc length & $3 \mathrm{~mm}$ & $3 \mathrm{~mm}$ \\
Voltage & $10.7 \mathrm{~V}$ & $10.7 \mathrm{~V}$ \\
Current & $145 \mathrm{~A}$ & $65 \mathrm{~A}$ \\
Welding speed & $3 \mathrm{~mm} / \mathrm{s}$ & $7 \mathrm{~mm} / \mathrm{s}$ \\
Shielding gas & $\mathrm{Ar}, 10 \mathrm{~L} / \mathrm{min}$ & $\mathrm{Ar}, 10 \mathrm{~L} / \mathrm{min}$ \\
Shielding cup diameter & $8 \mathrm{~mm}$ & $8 \mathrm{~mm}$ \\
\hline
\end{tabular}

and scanning electron microscopy (SEM) studies. Three etching procedures were followed to clearly delineate the microstructrual constituents present in the weldments. In the first, samples were etched with 4 pct Nital solution for 5 seconds. The second was carried out using 10 pct Picral solution for 90 seconds for better delineation of prior austenite grain boundaries. The third etching method was used to examine the presence of RA in the microstructure. In this method, samples were etched for 15 seconds with 4 pct Picral followed by 30 seconds etching in 1 pct sodium metabisulfite solution in water. This etching procedure changes the colors of the RA/martensite into bright whitish blue, bainite into brown, and allotriomorphic ferrite into a tan color. ${ }^{[7]}$ The samples were subsequently analyzed using optical microscopy.

Scanning electron microscopy was performed using a JEOL* JSM 6500F field emission gun (FEG) scanning

*JEOL is a trademark of Japan Electron Optics Ltd., Tokyo.

electron microscope in secondary electron imaging mode. Energy-dispersive spectroscopic (EDS) analysis was undertaken for qualitative examination of the alloying elements present.

A quantitative measurement of RA present in the welded samples was carried out by X-ray diffraction measurements using Co $K_{\alpha}$ radiation. The volume fraction of austenite in unwelded base metal, fusion, and HAZs ( $\sim 4 \mathrm{~mm}$ from weld centerline) was calculated from the integrated intensities of (111), (200), (220), and (311) austenite and (110), (200), (211), and (220) ferrite peaks by the internal standard method. ${ }^{[8]}$

The equilibrium phase diagrams and mass fraction of alloying elements in different phases of TRIP steels were calculated from the TCFE2 and SSOL2 database of the commercial thermodynamic software Thermocalc ${ }^{(}$ (Thermocalc software AB, Stockholm, Sweden). 


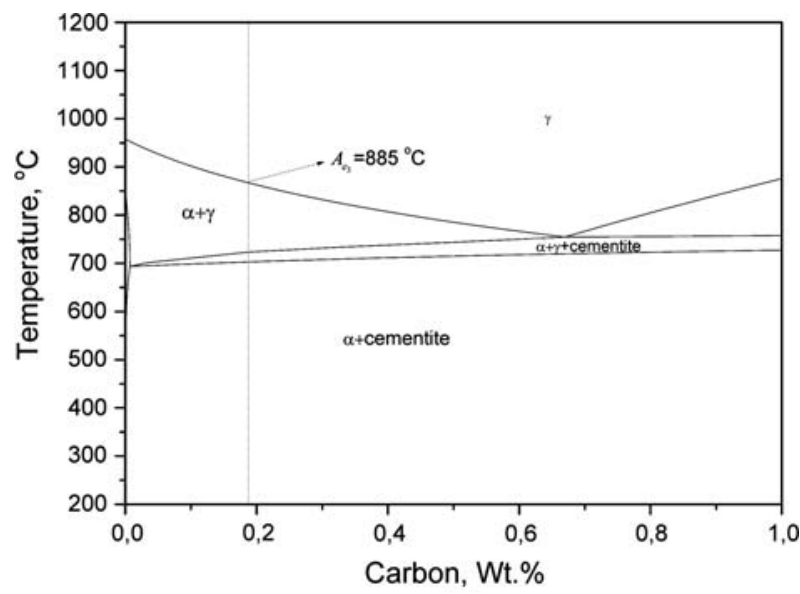

(a)

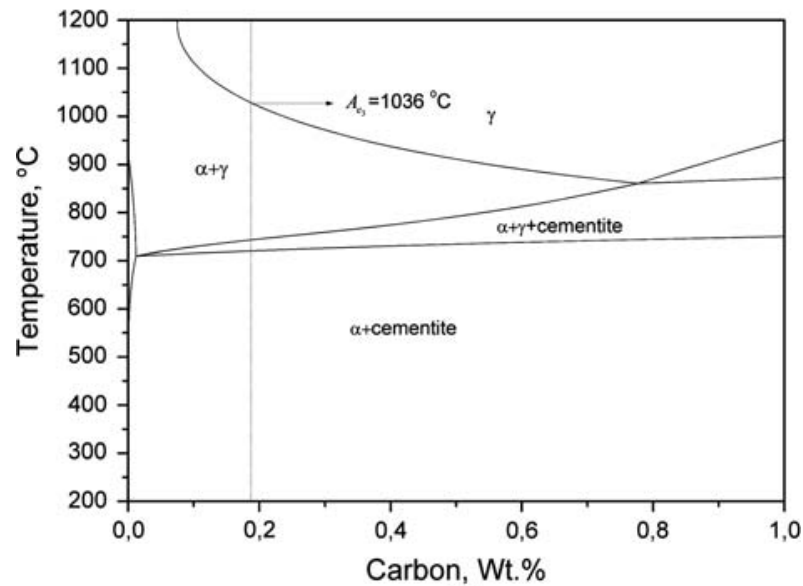

(b)

Fig. 1-(a) Pseudobinary phase diagram of high-Si TRIP steel. (b) Pseudobinary phase diagram of high-Al TRIP steel.

\section{RESULTS AND DISCUSSION}

\section{A. Characteristics of High-Si and High-Al Basemetals}

The phase transformation behavior of the high-Si and high-Al steels used here differ significantly in terms of their transformation temperatures and the phase fields (Figure 1). The $\mathrm{Ae}_{3}$ temperature of the high-Si is about $885^{\circ} \mathrm{C}$, whereas high-Al steel shows a higher $\mathrm{Ae}_{3}$ temperature $\left(1036{ }^{\circ} \mathrm{C}\right)$. The post-heat-treated microstructures of both steels show the presence of RA in a ferritic and bainitic microstructure (Figure 2).

\section{B. Thermal Profiles of GTA Welding}

Figure 3 shows the temperature variation across the width of the high-Si and high-Al steel plates during GTA welding. In the case of the high-Si steel weld, the width of the weld bead was about $5.5 \mathrm{~mm}$. The maximum temperature measured at a point $3.5 \mathrm{~mm}$ from the weld center was $1058{ }^{\circ} \mathrm{C}$. This measurement point had heating ranging from $200{ }^{\circ} \mathrm{C} / \mathrm{s}$ to $520{ }^{\circ} \mathrm{C} / \mathrm{s}$. A maximum temperature of $440{ }^{\circ} \mathrm{C}$ was measured $12 \mathrm{~mm}$ from the weld centerline with an average heating and cooling rate of $80{ }^{\circ} \mathrm{C} / \mathrm{s}$. The temperature variation

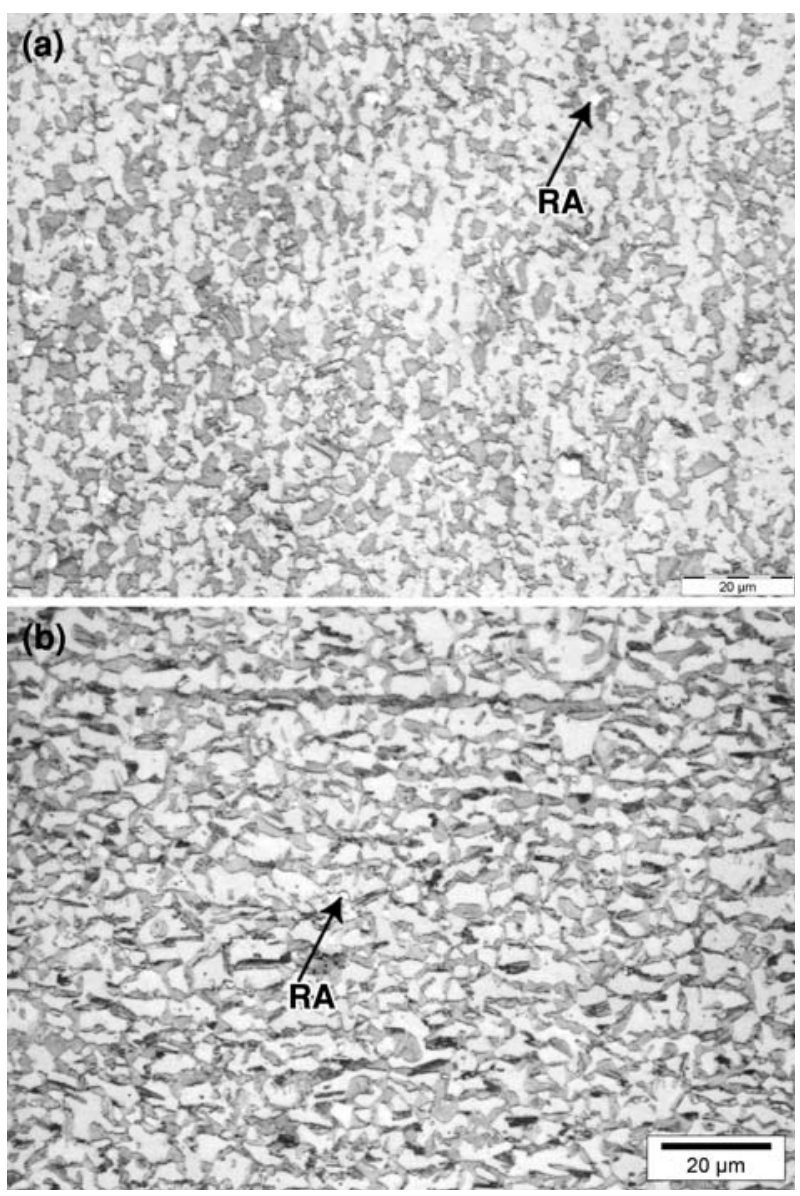

Fig. 2-(a) Microstructure of the high-Si steel after intercritical annealing at $840{ }^{\circ} \mathrm{C}$ and isothermal holding at $400{ }^{\circ} \mathrm{C}$, showing $\mathrm{RA}$ in bright color. (b) The microstructure of the high-Al steel after intercritical annealing at $840{ }^{\circ} \mathrm{C}$ and isothermal holding at $400{ }^{\circ} \mathrm{C}$, showing RA in bright color.

across the width of high-Al steel weld is shown in Figure 3(b). The maximum temperature at the point $2.6 \mathrm{~mm}$ from the weld centerline is $980{ }^{\circ} \mathrm{C}$, where maximum heating and cooling rates $\left(200{ }^{\circ} \mathrm{C}\right.$ to $550{ }^{\circ} \mathrm{C} / \mathrm{s}$ ) were also observed. The width of the $\mathrm{FZ}$ was $5 \mathrm{~mm}$.

\section{Microstructural Characteristics of Welded Steel Plates}

The average grain size in the coarse-grained zone in both steels is about $120 \mu \mathrm{m}$ (Figure 4). The FZs and HAZs of GTA-welded TRIP steels contain primarily a martensitic structure. Unlike the high-Al steel weld, the coarse-grained HAZ in the high-Si steel did not show the presence of allotriomorphic ferrite at the fusion line and grain boundaries.

The FZs of both steels show the presence of inclusions, mainly with a random distribution and in some places decorating the grain boundaries. The average sizes of the inclusions in the FZ of the high-Si steel are found to be smaller in size compared with those found in the high-Al FZ. A zone of soft allotriomorphic ferritic grains was found across the fusion line of the high-Al 


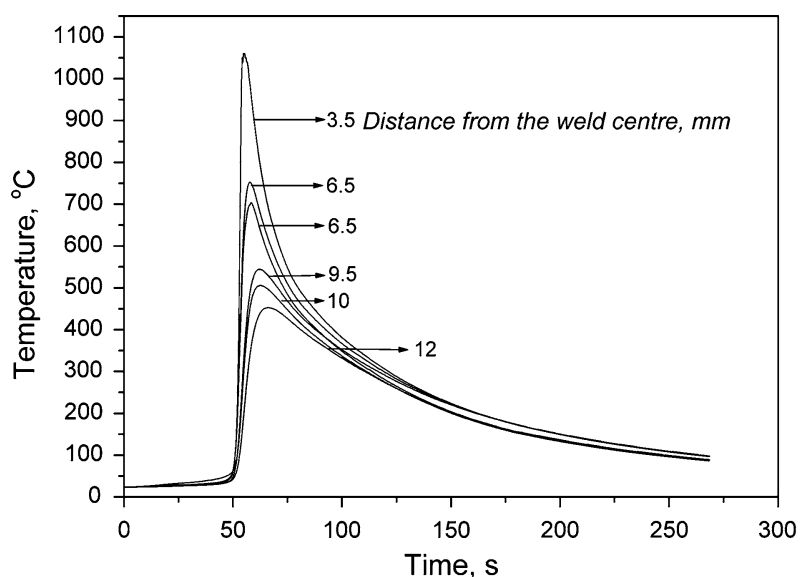

(a)

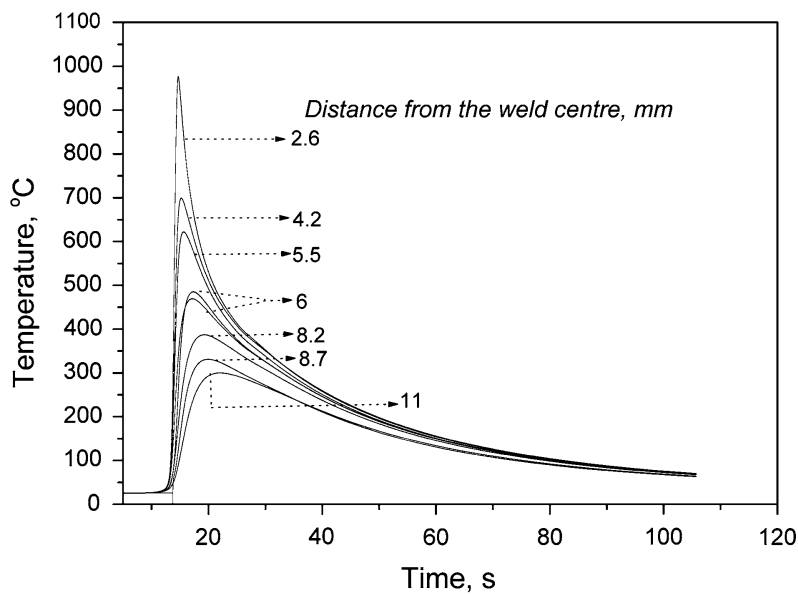

(b)

Fig. 3-(a) Thermal cycle during GTA welding of high-Si steel plate. (b) Thermal cycle during GTA welding of high-Al steel plate.

steel weld (Figure 4(b)). In TRIP steels, the formation of hard intermetallic inclusions in the FZ and the presence of soft ferritic grains at the fusion line are invariably detrimental to the mechanical properties.

\section{Inclusions in the FZ}

The FZs of both high-Si and high-Al steels contain complex inclusions. The optical microscopic studies show that these inclusions are generally found at the grain boundaries and occasionally they have also been seen in the grain interiors. Figure 5(a) gives an overview of the presence of inclusions in the FZ of a high-Si weld and shows that the columnar grain boundaries are decorated with inclusions. At the center of the FZ, the presence of inclusions is also found inside the equiaxed grains. The inclusion density at the center of the high-Si weld zone is lower than in the columnar grain zones (Figure 5(a)-ii and 5 (b)).

Inclusions in the high-Al welds show a similar distribution behavior to the high-Si steel welds. However, the inclusions in the high-Al steel weld are found to be larger in size and higher in volume fraction (Figure 5(c))
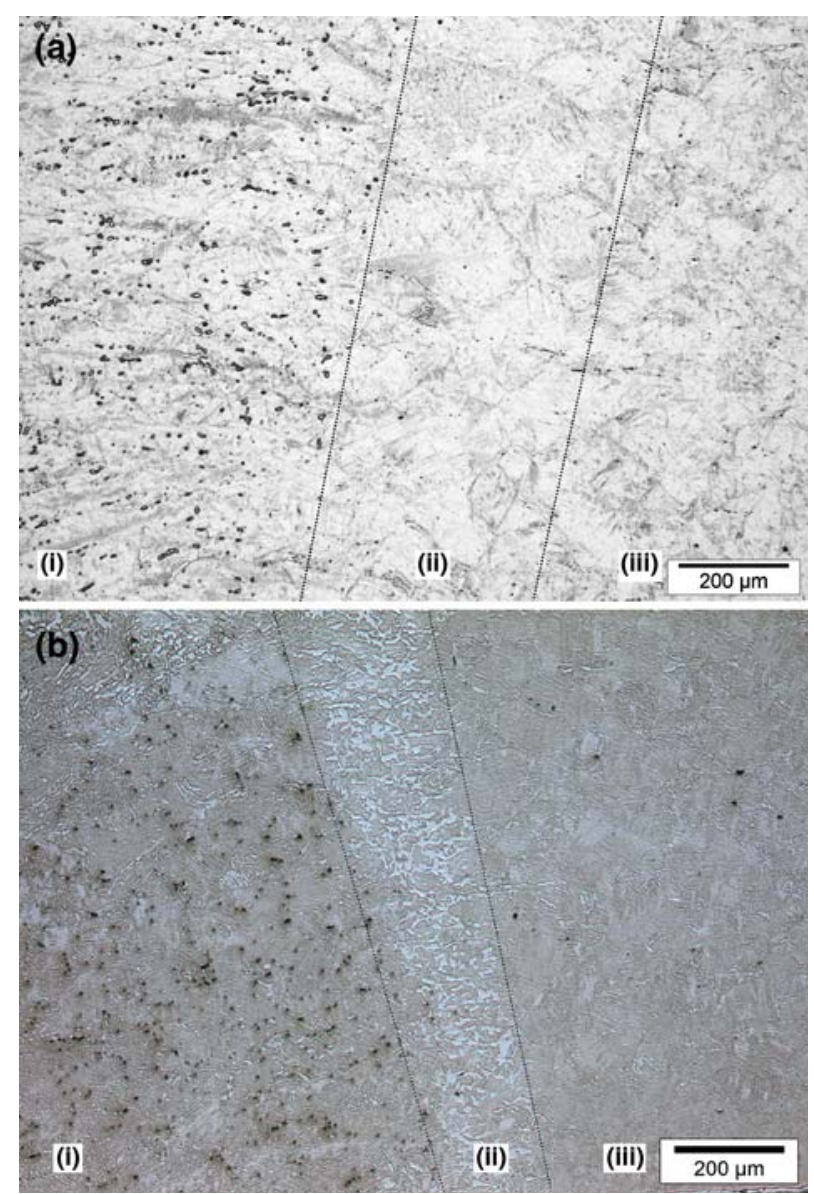

Fig. 4-(a) Optical micrograph of high-Si steel weld showing martensitic structure and the presence of inclusions in (i) FZ, (ii) coarse-grained HAZ, and (iii) fine-grained HAZ. (b) Optical micrograph of high-Al weld showing (i) inclusion-contained FZ, (ii) ferritic fusion line, and (iii) coarse-grained HAZ with grain boundary ferrite.

\section{E. Ferrite Formation in the FZ of High-Al Steel Welds}

The microstructural analysis of high-Al TRIP steel welds revealed the formation of allotriomorphic ferrite at the fusion lines and the grain boundaries in the FZs (Figure 6). This ferritic formation was not observed in the high-Si TRIP steel welds. The EDS analysis shows that this ferrite contains higher amounts of aluminum than the base metal (Figure 7).

\section{F. Inclusion Formation}

The observation of inclusions in the FZs of low alloyed steel welds is not new; in fact, extensive research had been performed in the past to study the formation mechanism of inclusions, their effects on subsequent phase transformations, and the final mechanical properties of the welds. ${ }^{[9-13]}$ Recent work on the microstructural evolution during welding of low-alloyed automotive grade steel such as dual-phase (DP) steels did not find any inclusion formation in the FZ. ${ }^{[14]}$ However, in TRIP steels, which exhibit superior mechanical properties compared with many other low-alloyed automotive grade steels, the presence of 

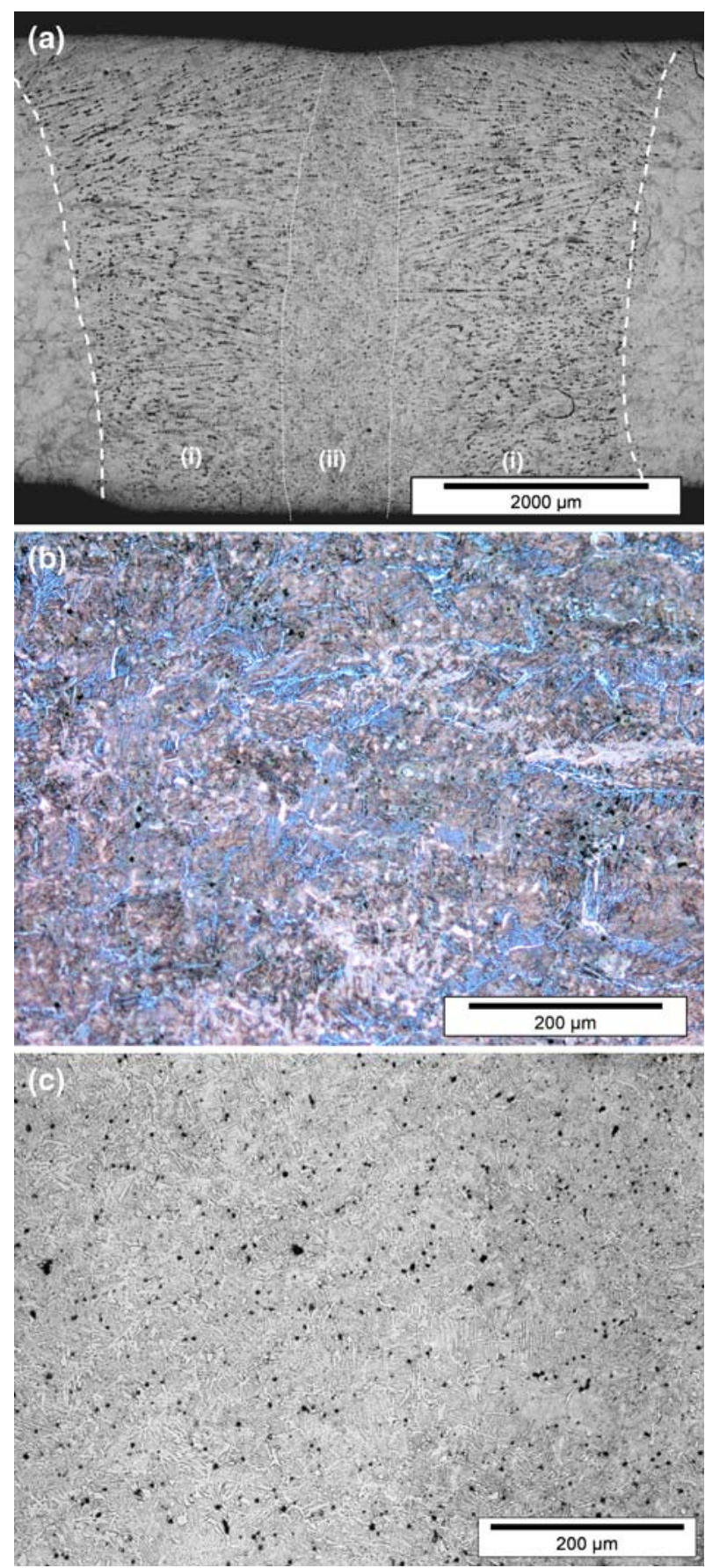

Fig. 5-(a) Optical micrograph of high-Si FZ showing (i) inclusions decorating columnar grain boundaries and (ii) inclusions in the equiaxed zone. (b) Inclusions in the weld center zone of high-Si weld showing a lower density and random distribution in comparison to columnar grain zones. (c) Inclusions in the weld center zone of highAl weld, showing a coarse and more dense distribution compared with the high-Si steel weld centerline.

inclusions is detrimental to elongation and strength of the welds. Thus, an extensive SEM examination coupled with energy dispersive analysis was performed on these inclusions to study their nature and the possible formation mechanism during welding. The morphologies of the inclusions present in the high-Si and high-Al

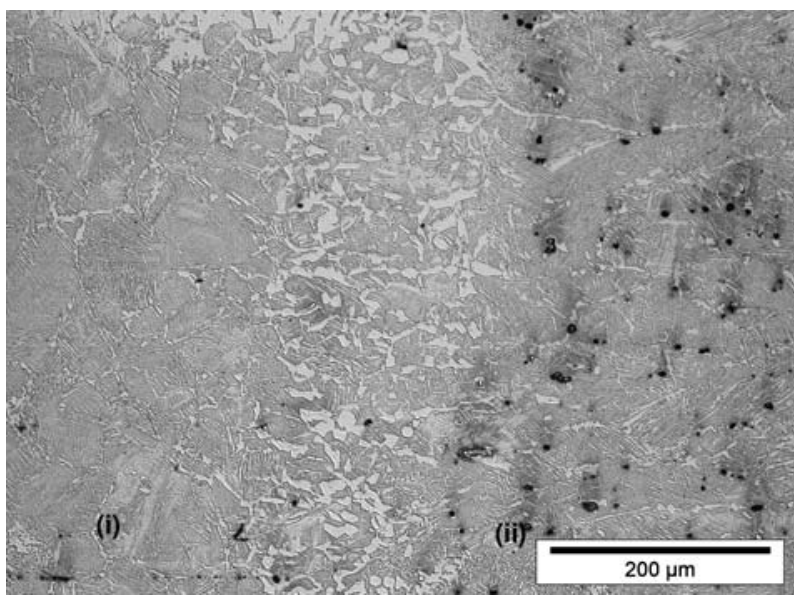

Fig. 6-Ferrite formation in the FZ of high-Al TRIP steel weld: (i) $\mathrm{HAZ}$ and (ii) $\mathrm{FZ}$.
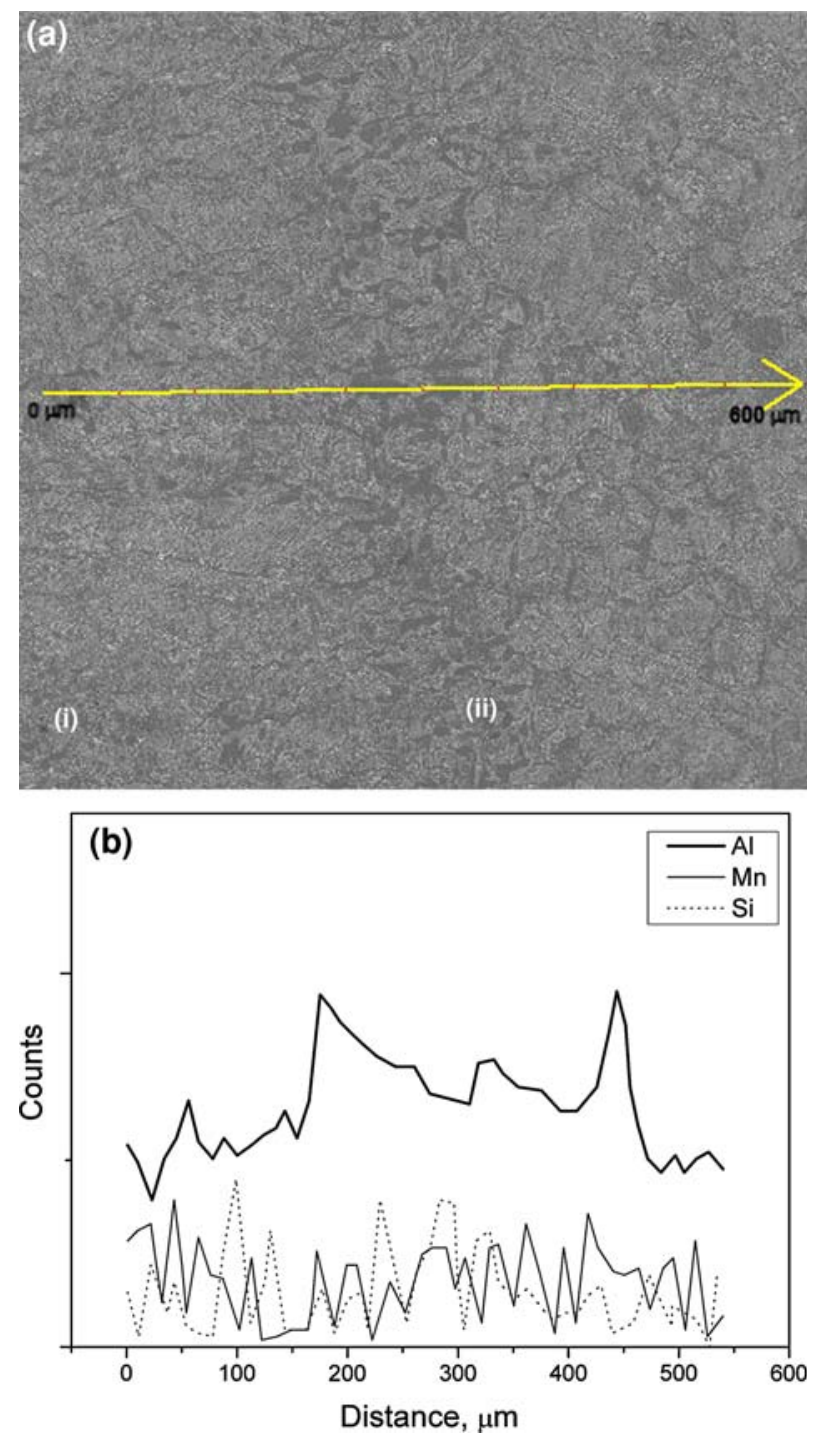

Fig. 7-(a) Microstructure of high-Al weld (i) FZ and (ii) ferritic fusion line. (b) Energy-dispersive X-ray analysis shows that the ferritic grains found on the FZ of high-Al steel welds show a higher amount of aluminum. 

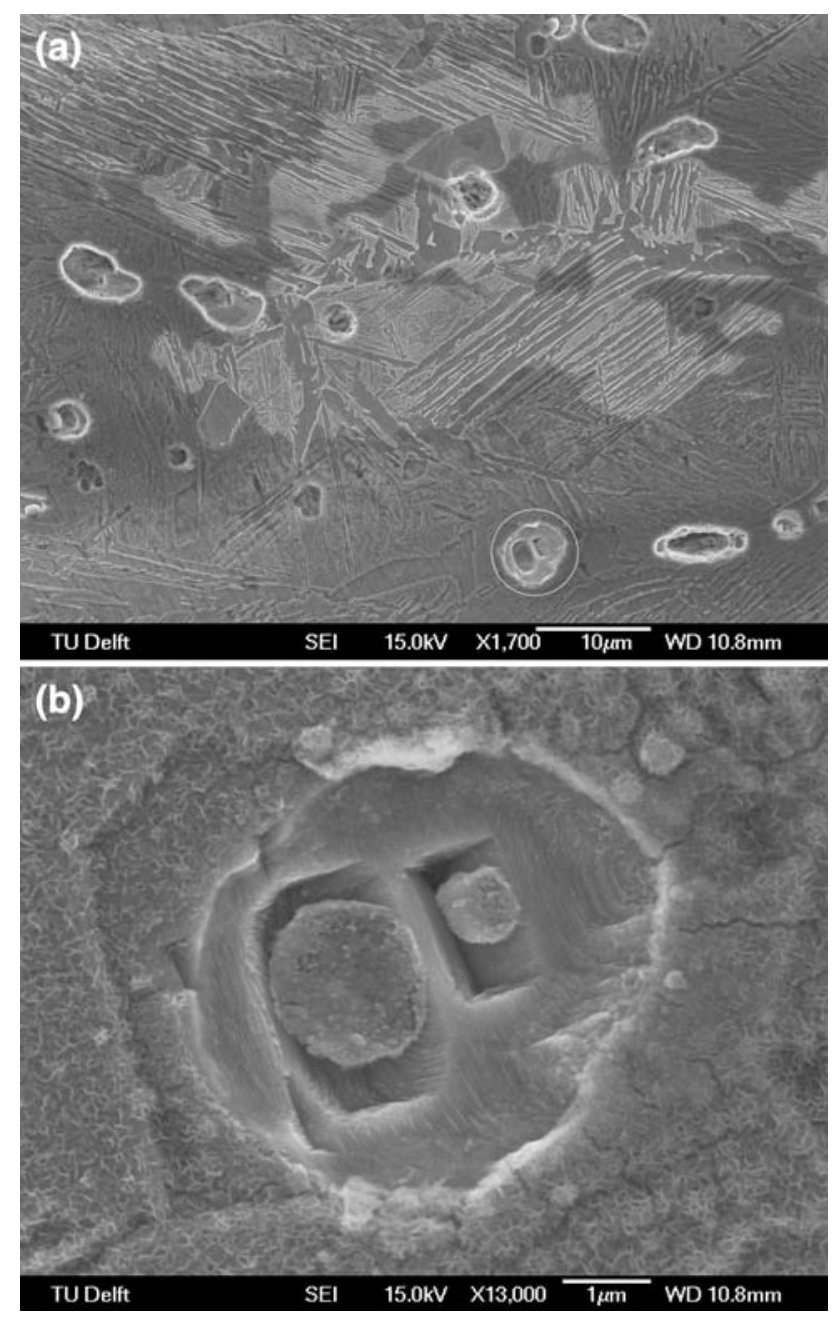

Fig. 8- (a) SEM image of the inclusions in high-Si weld (encircled region is shown magnified in b). (b) Inclusion in the FZ of high-Si shows the presence of several substructures.

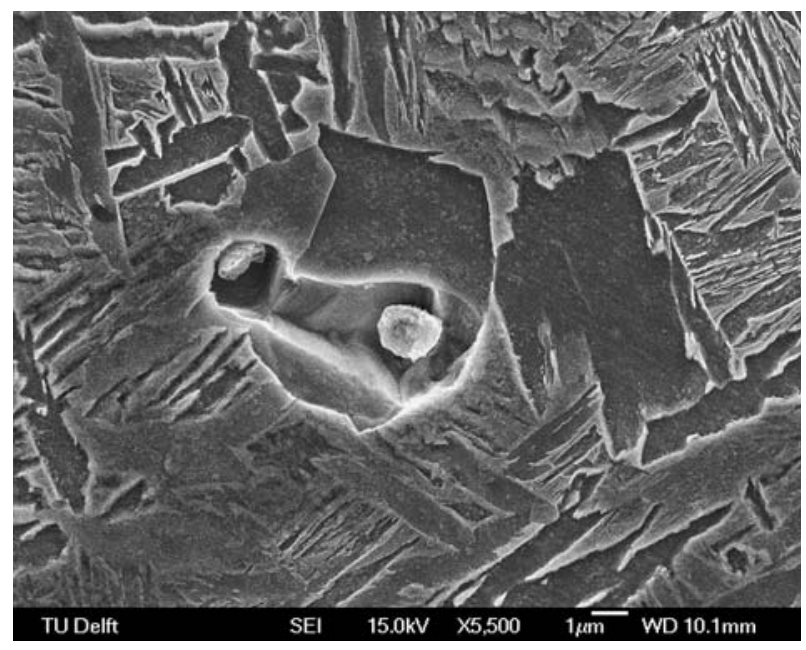

Fig. 9-Inclusions in high-Al steel weld show similar morphologies as seen in high-Si steel weld.

TRIP steel welds are shown in the scanning electron micrographs (Figures 8 and 9). These images clearly indicate that the inclusions are not single structural
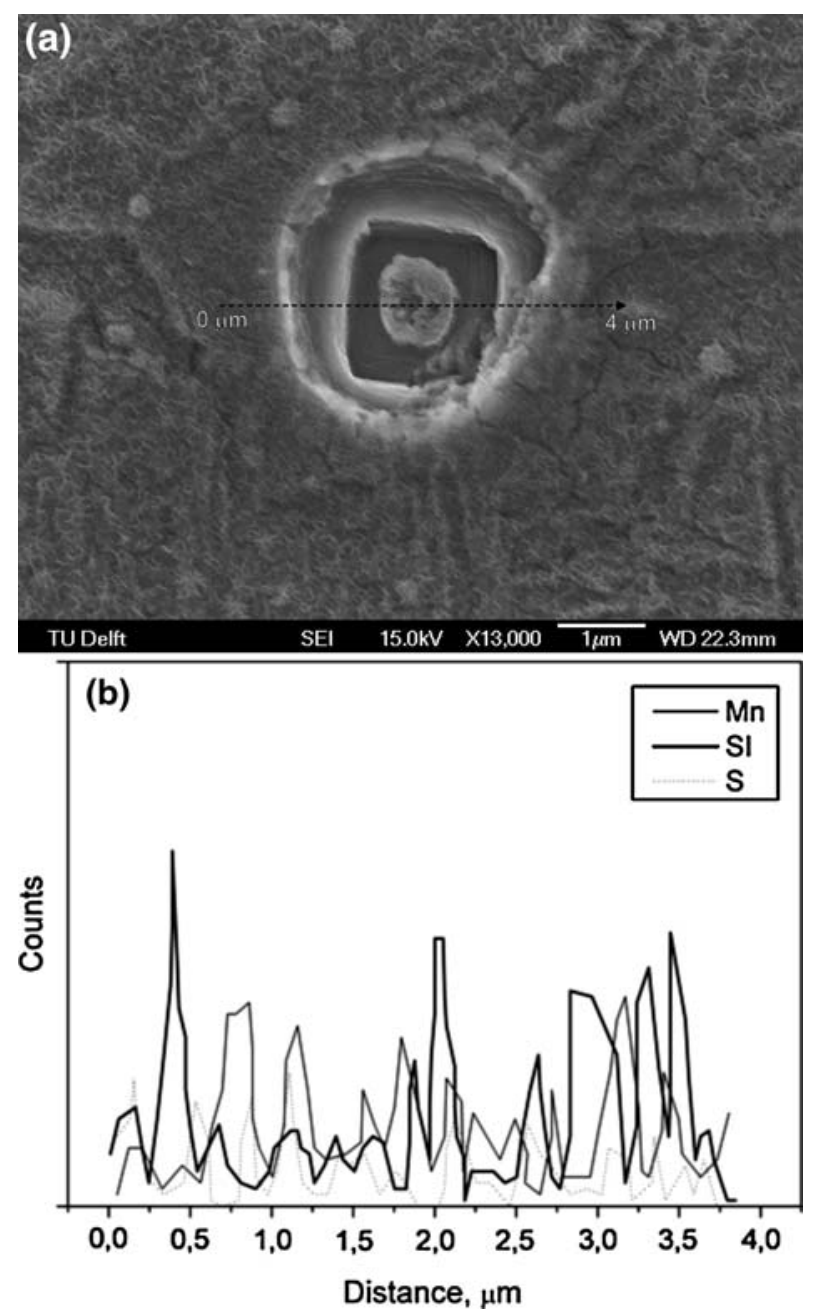

Fig. 10 - (a) Energy-dispersive X-ray analysis of high-Si steel weld inclusions $(b)$ showing a silicon-rich core.

entities but are comprised of several small substructural features.

It is known that the first reaction that influences the final weld microstructure is inclusion formation, and the presence of strong deoxidizers such as silicon and aluminum in high amounts, as in the case of the TRIP steels under investigation, leads to the formation of oxide inclusions during welding. ${ }^{[9-13]}$ It is also known that the reaction between the dissolved alloying elements in the weld pool with the available oxygen, nitrogen, and carbon forms nonmetallic inclusions. In TRIP steels, strong oxidizing elements such as $\mathrm{Al}$ and $\mathrm{Si}$ are added to suppress the formation of cementite and thereby to stabilize the austenite by enriching it with carbon: ${ }^{[1]}$ however, due to the strong affinity for oxygen, the added $\mathrm{Al}$ and $\mathrm{Si}$ readily form oxides during welding, leaving the weld pool depleted of these elements. This can be seen from Figure 10, where the energy-dispersive elemental analysis of the inclusions present in the FZ of the high-Si steel shows a higher silicon concentration at the center core as well as at the sides of the inclusion. Although the bulk manganese content is higher than 

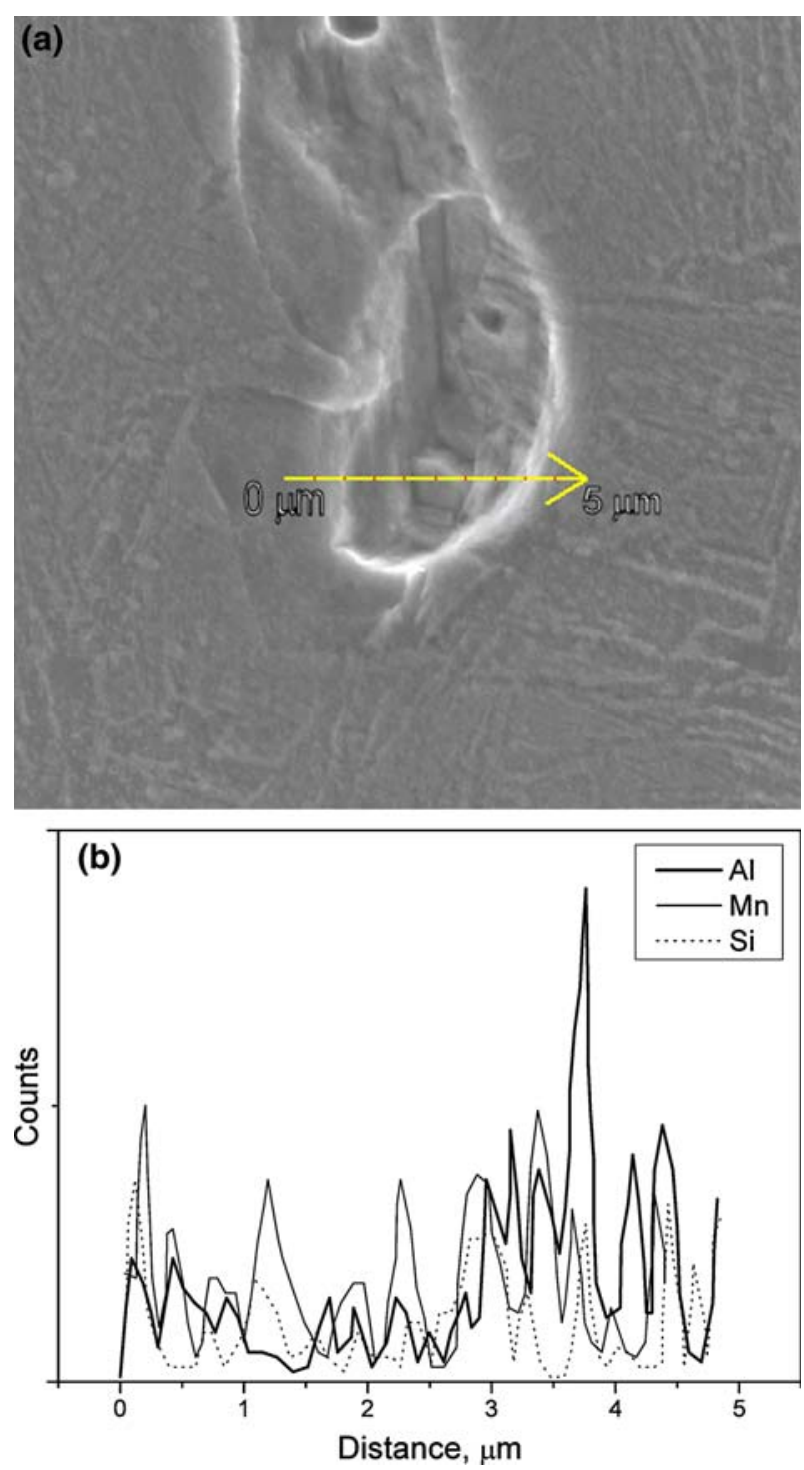

Fig. 11-(a) Inclusions in high-Al steel weld $(b)$ shows more aluminum at core. (Note: Inclusion is not in the plane of observation.)

that of silicon, the amount of manganese found in the inclusion is less than that of silicon, while the variation is found to be similar. Similar behavior in elemental distribution was found in high-Al steel weld inclusions, where the cores were found to be richer in aluminum (Figure 11).

During welding, aluminum present in the liquid weld pool combines with available atmospheric oxygen and forms oxides, due to its higher affinity to oxygen compared with silicon. The formation of aluminum oxides leads to solute entrapment in its surroundings and to the subsequent formation of silicon oxides and epitaxially grown manganese sulfides when the liquid weld pool cools below the solidification temperature. The EDS analysis of inclusions in the high-Al steel FZ (Figure 11) confirms this mechanism, where the aluminum content is found to be higher at the center core of the inclusion. In the case of high-Si steel, which contains

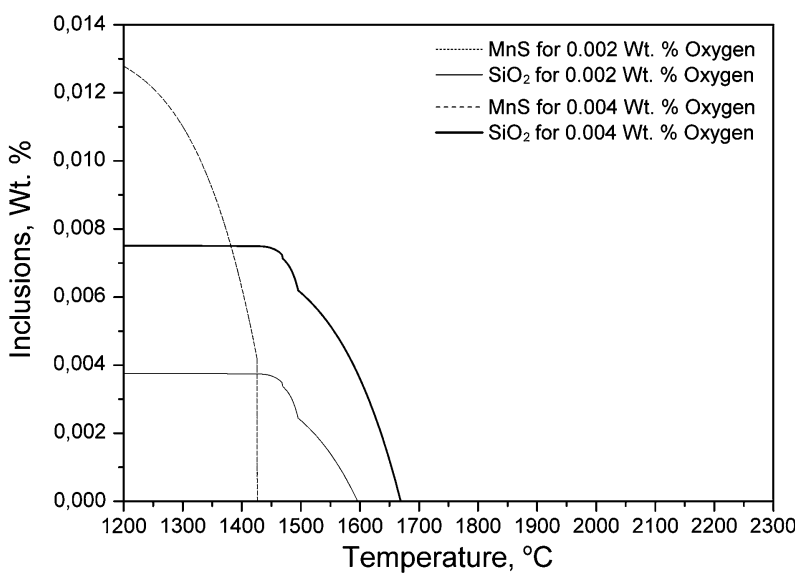

(a)

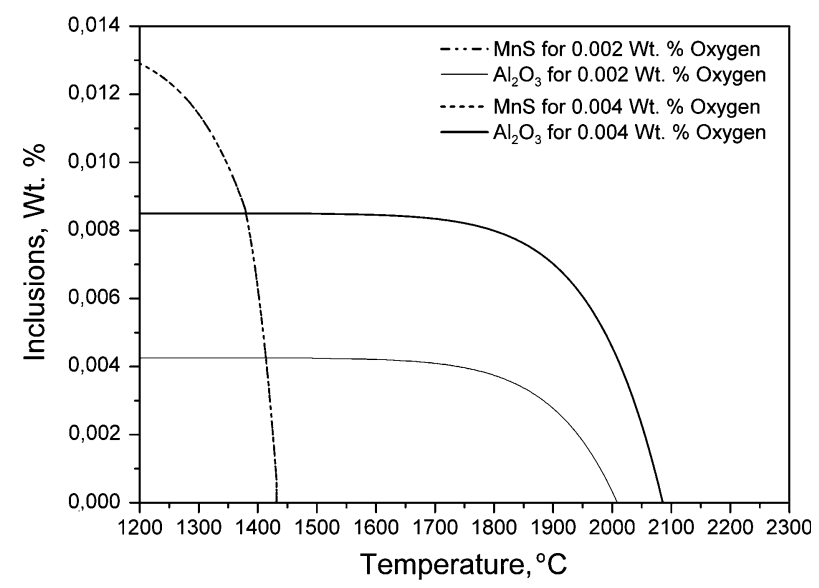

(b)

Fig. 12-Equilibrium inclusion stability diagrams for two different oxygen contents: $(a)$ high-Si steel and $(b)$ high-Al steel.

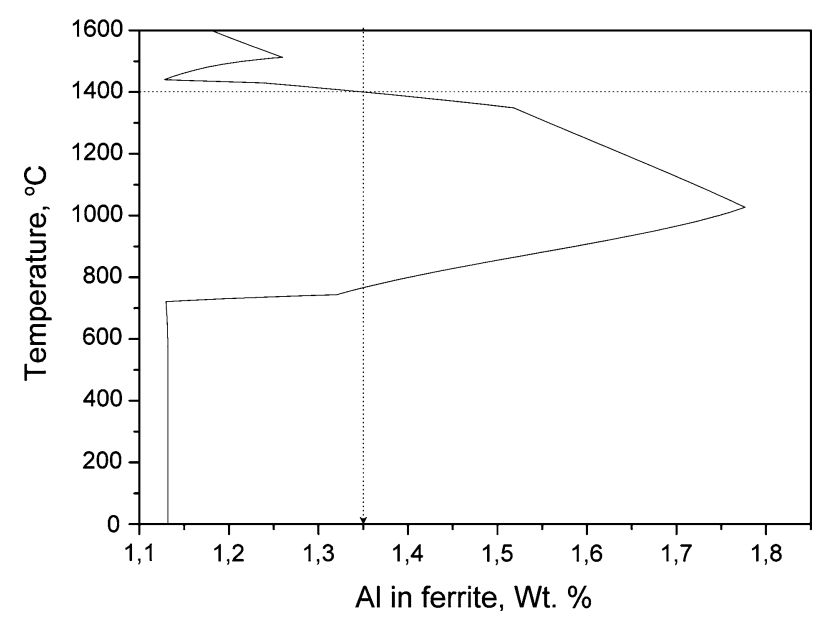

Fig. 13-Equilibrium aluminum content in ferrite of high-Al TRIP steel, showing that at $1400{ }^{\circ} \mathrm{C}$, ferrite in TRIP steel can have $1.35 \mathrm{wt}$ pet of aluminum.

only silicon as a strong deoxidizing element, the oxides of the silicon generally form at a lower temperature than those of aluminum, and the average size of the 
inclusions in the high-Si steel welds is therefore smaller. This can also be confirmed from Figure 12, where equilibrium inclusion contents are given with respect to temperature for both steels with two different oxygen contents. Figure 12(b) indicates that for high-Al steel weld pool with an oxygen content of $0.002 \mathrm{wt}$ pct, the nucleation temperature of $\mathrm{Al}_{2} \mathrm{O}_{3}$ is found to be $2008{ }^{\circ} \mathrm{C}$, whereas in high-Si steel, $\mathrm{SiO}_{2}$ is found to nucleate at $1596{ }^{\circ} \mathrm{C}$ (Figure 12(a)). If the oxygen content of the weld pool increases from 0.002 to $0.004 \mathrm{wt}$ pct, the nucleation temperature of oxides increases by about $75^{\circ} \mathrm{C}$ in both steels. In all cases, $\mathrm{MnS}$ appears to form at about $1425^{\circ} \mathrm{C}$ and the oxygen content in liquid steel is not found to affect the formation of $\mathrm{MnS}$.

\section{G. Ferrite Formation}

The aluminum-based TRIP steels, as in the case of the current high-Al TRIP steel under investigation, generally contain about 1 to $1.3 \mathrm{wt}$ pet of aluminum in order to suppress the formation of iron carbides and stabilize the austenite at room temperature. During welding and subsequent solidification of the molten weld pool, the equilibrium aluminum content in ferrite can rise as high as $1.35 \mathrm{wt}$ pct at $1400{ }^{\circ} \mathrm{C}$ for the steel under consideration (Figure 13). According to the corresponding binary $\mathrm{Fe}-\mathrm{Al}$ phase diagram, if the aluminum content exceeds 1.15 wt pct, the ferrite is stabilized (Figure 14). When the liquid weld pool starts to solidify to $\delta$ ferrite at the fusion lines and at the columnar grain boundaries, the aluminum starts to partition to the newly solidified $\delta$ ferrite from the liquid weld pool. Once the aluminum in the $\delta$ ferrite reaches the critical stabilization limit ( $1.15 \mathrm{wt} \mathrm{pct}$ ), the $\delta$ ferrite stabilizes at the fusion lines and at the grain boundaries and does not undergo any further transformation into intercritical austenite and subsequent martensite. Thus, soft ferritic zones are formed close to the fusion lines and columnar grain boundaries. The hardness variation across the FZs and HAZs of high-Al welds is shown in Figure 15. It can be seen that the presence of soft ferrite causes a dip in the hardness profile close to the fusion line as well as in a few areas in the FZ.

\section{H. Variation of RA Content Welded TRIP Steels}

Table III shows the volume fraction of RA present in the base metal, HAZs, and FZs of high-Si and high-Al TRIP steels measured by X-ray diffraction analysis.

It can be seen from the table that very little austenite is stabilized within the FZs of TRIP steels. This is due to the fact that formation of complex inclusions during welding of TRIP steels leaves very low concentrations of dissolved alloying elements such as silicon and aluminum in the weld pool to stabilize the austenite. Due to this, the purpose of silicon and aluminum additions is lost, because they are no longer effective in suppressing the formation of iron carbides. This ultimately leads to the depletion of dissolved carbon in the weld pool, which results in less austenite in the FZs. ${ }^{[1]}$

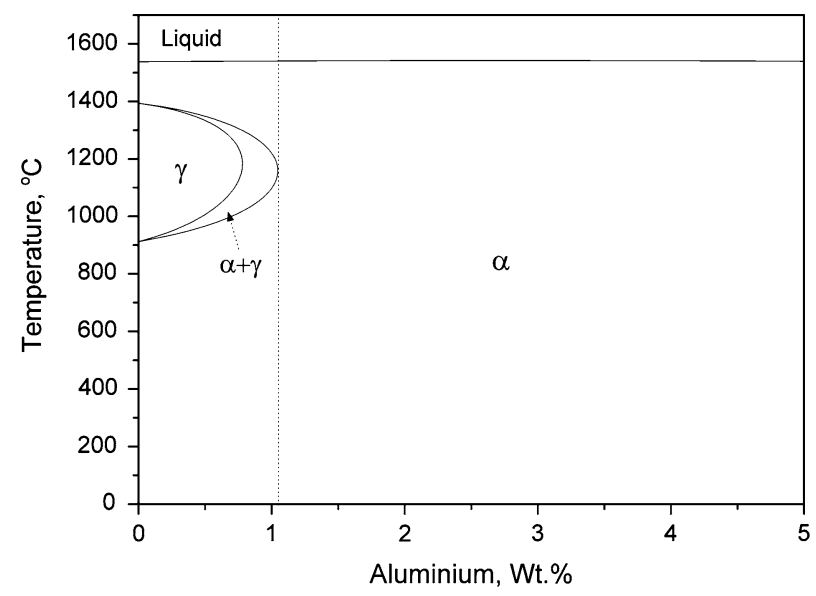

Fig. 14-The binary Fe-Al phase diagram shows that if aluminum in steel goes beyond $1.2 \mathrm{wt}$ pct, ferrite is stabilized.

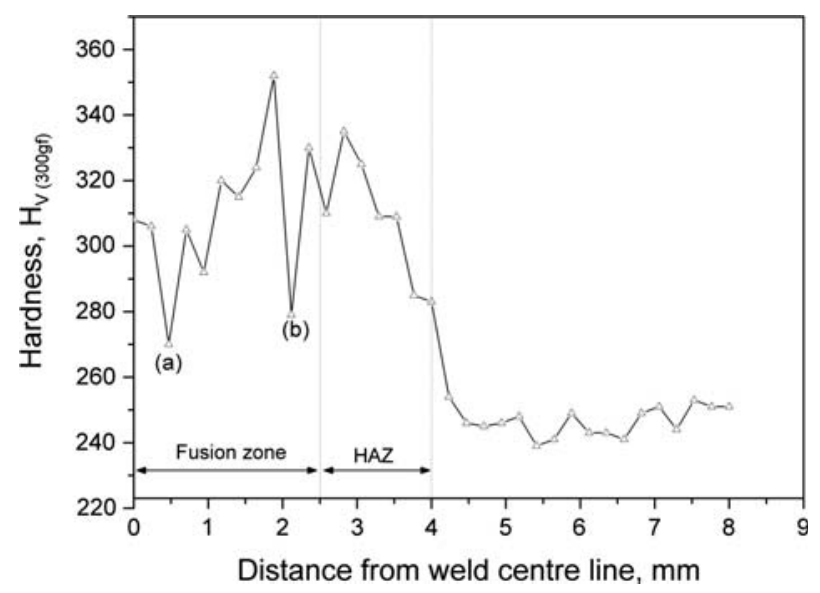

Fig. 15-Hardness variation across the high-Al TRIP steel weld shows the presence of lower hardness area $(a)$ in the FZ and $(b)$ close to the fusion line.

Table III. Variation of RA Content (Volume Percent) in High-Si and High-Al TRIP Steels

\begin{tabular}{lccc}
\hline & & HAZ (6 mm from & \\
Steel & Base Metal & Weld Centerline) & FZ \\
\hline High-Si & 10 & 8 & 4 \\
High-Al & 11 & 8 & 5 \\
\hline
\end{tabular}

\section{CONCLUSIONS}

Microstructural analysis of welded silicon- and aluminum-based TRIP steels shows the formation of complex inclusions in the FZs of high-Si and high-Al TRIP steels. These inclusions are found to be comprised of several substructural features with different compositions. The formation of allotriomorphic ferrite is found at the fusion line and the grain boundaries of high-Al steel welds. Partitioning of aluminum to the solidified $\delta$ ferrite leads to stabilization of ferrite at the 
fusion lines and columnar grain boundaries. The RA content in the FZs of TRIP steel welds is about 4 pct by volume, whereas the base metal austenite content is about 10 pet by volume.

While it is possible to say that high-Al TRIP steel is poorer to weld because it forms coarse inclusions in the FZ and a soft ferritic zone at the fusion lines compared with the high-Si TRIP steel, which showed only the formation of inclusions in the FZ, further experimental evidence should be sought in terms of mechanical behavior of the welds with varying aluminum and silicon contents to optimize the TRIP steel chemistry for better weldability.

\section{ACKNOWLEDGMENTS}

This research was carried out under Project No. MC8.04188 in the framework of the Research Program of the Materials Innovation Institute M2 $\mathrm{i}$ (www.m2i.nl), the former Netherlands Institute for Metals Research.

\section{OPEN ACCESS}

This article is distributed under the terms of the Creative Commons Attribution Noncommercial License which permits any noncommercial use, distribution, and reproduction in any medium, provided the original author(s) and source are credited.

\section{REFERENCES}

1. B.C. De Cooman: Curr. Opin. Solid State Mater. Sci., 2004, vol. 8 , pp. $285-303$.

2. P.J. Jacques: Curr. Opin. Solid State Mater. Sci., 2004, vol. 8, pp. 259-65.

3. L. Cretteur and A.I. Koruk: Mater. Sci. Forum, 2003, vols. 426432, pp. 1225-30.

4. L. Cretteur, A. Koruk, and L. Tosal-Martines: Steel Res., 2002, vols. 6-7, pp. 314-19.

5. T.-K. Han, S. Sang Park, K.-H. Kim, C.-Y. Kang, I.-S. Woo, and J.-B. Lee: ISIJ Int., 2005, vol. 45 (1), pp. 60-65.

6. T.-K. Han, K.-H. Kim, B.-L. Kim, C.-Y. Kang, I.-S. Woo, and J.-B. Lee: Mater. Sci. Forum, 2004, vols. 449-452, pp. 409-12.

7. E. Girault, P. Jacques, P. Harlet, K. Mols, J. Van Humbeeck, E. Aernoudt, and F. Delannay: Mater. Characterization, 1998, vol. 40 , pp. $111-18$.

8. B.D. Cullity and S.R. Stock: Elements of X-Ray Diffraction, 3rd ed., Prentice Hall, Englewood Cliffs, NJ, 2001, pp. 355-58.

9. S.S. Babu and S.A. David: ISIJ Int., 2002, vol. 42 (12), pp. 1344 53.

10. T. Kosekil and G. Thewlis: Mater. Sci. Technol., 2005, vol. 21 (8), pp. 867-79.

11. H. Yin: Iron Steel Technol., 2006, June, pp. 64-73.

12. M.A. Quintana, J. McLane, S.S. Babu, and S.A. David: Weld. Res. Suppl., 2001, Apr., pp. 98s-105s.

13. T. Hong, T. DebRoy, S.S. Babu, and S.A. David: Metall. Mater. Trans. B, 2000, vol. 31B, pp. 161-69.

14. C. Ma, D.L. Chen, S.D. Bhole, G. Boudreau, A. Lee, and E. Biro; Mater. Sci. Eng. A, 2008, vol. 485, pp. 334-46. 